\title{
ACTUALIZACIÓN EN EL TRATAMIENTO DE LA MENINGITIS NEONATAL BACTERIANA Y REPORTE DE UN CASO
}

\author{
Andrés Mauricio Állvarez Pinzón M.D. ${ }^{1}$, Mayerli Rodríguez Martínez M.D. ${ }^{2}$, Gustavo Charria Ortiz M.D. ${ }^{3}$ \\ ${ }^{1}$ Universidad El Bosque, Bogotá, Colombia, ${ }^{2}$ Universidad Militar Nueva Granada, Bogotá, Colombia. ${ }^{3}$ División \\ de Neurología Infantil, Universidad de Miami, Escuela de Medicina "Leonard Miller", Miami (FL), USA
}

\begin{abstract}
Resumen
La meningitis neonatal bacteriana es una de las enfermedades infecciosas que más se asocia a altas tasas de morbi-mortalidad en los individuos afectados. Aunque esta entidad se presenta a nivel mundial, su incidencia y prevalencia son más altas en los países en vía de desarrollo, debido a la falta de un adecuado control prenatal, que es uno de los factores asociados. En los últimos diez años se ha contado con la disponibilidad de agentes antibacterianos efectivos, que han permitido notables avances en su tratamiento ayudando a minimizar la severidad del cuadro clínico y/o secuelas y por lo consiguiente, a un mejor pronóstico y a la disminución de la mortalidad asociada; sin embargo, esta enfermedad sigue siendo frecuente, lo que hace pensar que la clave de un buen pronóstico radica tanto en su prevención, que se basa en la detección, y tratamiento precoz antes de la colonización del agente infeccioso en los gestantes, como en un buen diagnóstico clínico y la confirmación por estudios paraclínicos, que permitirán seleccionar el tratamiento adecuado. Los principales agentes causales siguen siendo el Streptococcus agalactiae (Grupo B), bacilos gram negativos, Listeria monocytogenes y Streptococcus pneumoniae. Los factores de riesgo son el parto pretérmino (menor a 37 semanas), la ruptura prematura de membranas mayor a 18 horas, o una temperatura materna mayor o igual a $38^{\circ} \mathrm{C}$ en el momento del parto. Aunque el manejo final deberá basarse en el resultado del antibiograma de las muestras de los hemocultivos, el tratamiento empírico iniciado con penicilinas más una cefalosporina de tercera generación y/o un aminoglucósido tipo gentamicina preferencialmente, después de haberse tomado las muestras, es el que ha mostrado la mejor de las respuestas clínicas. El tratamiento endovenoso deberá continuarse con el antibiótico apropiado para el germen aislado, hasta dos semanas después de la negativización del hemocultivo. Desafortunadamente, las secuelas severas a largo plazo son frecuentes ( $12 \%$ a $29 \%$ de los afectados), especialmente en las infecciones asociadas a Streptococcus del grupo B y a bacilos gram negativos, aún en los casos en los que el tratamiento ha sido oportuno y adecuado.
\end{abstract}

Palabras clave: meningitis, neonato, Streptococcus agalactiae, Listeria monocytogenes, Streptococcus pneumoniae

\section{NEONATAL BACTERIAL MENINGITIS TREATMENT UPDATE AND REPORT OF A CASE}

\begin{abstract}
Neonatal bacterial meningitis is one of the infectious diseases most commonly associated with high rates of morbidity and mortality in affected individuals. Although this entity is present worldwide, its incidence and prevalence are much higher in developing countries due to the lack of adequate prenatal care, which constitutes one of the associated factors. During the last decade more effective antibacterial
\end{abstract}

* Correspondencia: Andrés Maurico Álvarez mauricioalvarez07@yahoo.com. Dirección Correspondencia: 9000 Royal Palm Blvd. E604 Coral Springs, FL 33065.

Recibido: Marzo 3 de 2010 Aceptado: Junio 14 de 2010. 
agents have enabled remarkable advances in treatment of this pathology, helping to minimize the severity of the clinical and/or its consequences and hence aiding to achieve a better prognosis and a decrease in the associated mortality. However, this pathology is still common; suggesting that the key to a good prognosis relies in its prevention, which in turns requires early detection and treatment of the infectious agent together with a good clinical diagnosis and confirmation by paraclinical studies, all of these will allow the selection of adequate treatment. The main causative agents remain: the Streptococcus agalactiae (Group B), gram negative bacilli, Listeria monocytogenes and Streptococcus pneumoniae; and the risk factorsare are: preterm birth ( $<37$ weeks), premature rupture of membranes more than 18 hours, or a maternal temperature greater or equal to $38^{\circ} \mathrm{C}$ at the time of delivery. Although the final management should focus on the outcome of susceptibility in samples of blood cultures, empiric treatment with penicillin plus a third-generation cephalosporin or an aminoglycoside gentamicin type, preferably after samples are taken, have shown better clinical responses. The intravenous therapy of the appropriate antibiotic should be applied until two weeks after culture negativization. Unfortunately, even in cases with early and adequate treatment, the severe long-term sequelae are not uncommon (12\% to $29 \%$ of patients), although these have been associated mostly with the Group B Streptococcus and the gram negative bacilli.

Keywords: meningitis, neonate, Streptococcus agalactiae, Listeria monocytogenes, Streptococcus pneumoniae

\section{ATUALIZAÇÃO SOBRE O TRATAMENTO DA MENINGITE BACTERIANA NEONATAL E RELATO DE CASO}

\section{Resumo}

A meningite bacteriana neonatal é uma doença infecciosa mais comumente associada com altas taxas de morbidade e mortalidade em indivíduos afetados. Embora esta entidade está presente em todo o mundo, sua incidência e prevalência são muito mais elevados nos países em desenvolvimento como um dos fatores mais associados a ele é a falta de controle pré-natal adequado. Nos últimos dez anos tem se beneficiado da disponibilidade de medidas eficazes de agentes antibacterianos, que têm permitido avanços significativos no tratamento, ajudando a minimizar a gravidade do quadro clínico e / ou conseqüências e portanto, com melhor prognóstico e menor mortalidade associada; No entanto, esta doença ainda é prevalente, o que sugere que a chave para um bom prognóstico reside tanto na sua prevenção, baseado na deteç̧ão e tratamento precoce, antes da colonização do agente infeccioso em mulheres grávidas, como em um bom diagnóstico clínico e confirmação através de estudos de rastreio, que permite que você selecione o tratamento correto. Os principais agentes permanecem Streptococcus agalactiae (Grupo B), bacilos gram negativos, Listeria monocytogenes, Streptococcus pneumoniae, e seus fatores de risco também se manteve estável: parto prematuro ( $<37$ semanas), ruptura prematura de membranas mais de 18 horas, ou uma temperatura materna maior ou igual a $38^{\circ} \mathrm{C}$ no momento do parto. Embora a abordagêm definitiva se baseia no resultado de susceptibilidade em amostras de culturas de sangue, o tratamento empírico com penicilina, além de uma cefalosporina de terceira geração ou um tipo de aminoglicosídeo gentamicina, de preferência após a colheita de amostras, são aqueles que têm mostrado melhor resposta clínica. Esta terapia intravenosa deve continuarseen relação ao agente isolado, até duas semanas após sua negativação das culturas. Infelizmente, mesmo nos casos com tratamento adequado e precoce, as seqüelas graves a longo prazo não são incomuns ( $12 \%$ a $29 \%$ dos pacientes), embora estas tenham sido associados principalmente com o estreptococo do grupo $\mathrm{B} e$ os bacilos gram negativas.

Palavras-chave: meningite, recém-nascido, Streptococcus agalactiae, Listeria monocytogenes, Streptococcus pneumoniae 


\section{Introducción}

La meningitis neonatal bacteriana se define como el proceso infecto-inflamatorio agudo que compromete las leptomeninges (aracnoides y piamadre), confirmado por cultivos positivos del líquido cefalorraquídeo (LCR) o en su defecto, por la detección de antígenos capsulares bacterianos por la técnica de la reacción en cadena de la polimerasa (1). Estos últimos estudios paraclínicos deben ser interpretados con cautela, ya que por lo general se deben excluir organismos considerados como contaminantes tales como el Staphylococcus coagulasa negativo o la flora de la piel como el Streptococcus viridans, diphteroides u otros organismos presentes en forma mixta. Dada la relativa pobre maduración de la barrera hematoencefálica a esta edad, este tipo de afección por lo general hace parte de un cuadro clínico sistémico tal como la sepsis, ya que su presencia aislada es poco frecuente (2).

\section{Etiología}

Según los estudios del Ministerio de Protección Social y el Instituto Nacional de Salud en Colombia, los organismos más frecuentes son similares a los antes mencionados, incluyendo el Streptococcus agalactiae (Grupo B), la Escherichia coli y la Listeria monocytogenes (3). El Streptococcus agalactiae del grupo B (EGB) es un coco gram positivo que coloniza entre un 15 a $40 \%$ de las pacientes gestantes hacia el final del embarazo y neonatos. La transmisión al neonato ocurre por lo general antes del nacimiento o durante el trabajo de parto. Aunque menos frecuente, la transmisión persona a persona es también una fuente de infección en etapas posteriores (días a semanas).

Entre las bacterias entéricas gram negativas que son agente causal de meningitis se incluyen los habitantes comunes de la flora intestinal/vaginal tales como la Escherichia coli, Klebsiella spp, Enterobacter sakazakii, Citrobacter koseri, Salmonella spp, Proteus mirabilis, Pseudomonas spp y Serratia marcescens. Algunas cepas específicas parecen mostrar cierta predilección por este proceso; es así como la E. coli que tiene el antígeno polisacárido capsular dominante K1 $(3,4)$, causa el $80 \%$ de las meningitis. Otro ejemplo es el de la Listeria monocytogenes, un bacilo grampositivo, aerobio y móvil, que cuando infecta a las gestantes, un $65 \%$ presentan un pródromo sintomático claro previo al diagnóstico en el neonato, por lo general consistente en fiebre y/o diarrea de entre una a tres semanas. Por eso en estos casos, se sospecha que además de las vías de trasmisión ya descritas, también puede ser por vía transplacentaria, por vías ascendentes o durante el parto. De hecho, cuando la infección materna ocurre en los estadios tempranos del embarazo, esta puede asociarse a aborto $\mathrm{y} / \mathrm{o}$ parto pretérmino con amnionitis y/o óbito fetal (3). Aun así, la infección perinatal puede ser asintomática.

Las infecciones por otros agentes (incluyendo la flora vaginal común) tales como Staphylococcus epidermidis, S. hemoliticus, S. saprophyticus, S. schleiferi o $S$. lugdunensis son poco comunes, y si producen infección en el neonato es un hecho excepcional que invadan el LCR. Cuando esta se presenta, por lo general se acompaña de hemorragias intraventriculares en neonatos con muy bajo peso, en presencia de un cuerpo extraño tal -como una derivación ventrículo peritoneal-, o por contaminación en el espacio ventricular, ya sea directamente o después de un procedimiento neuroquirúrgico; estas variantes por lo general tienen un inicio tardío $(3,5)$. Los agentes etiológicos no parecen ser muy diferentes a los encontrados en los países desarrollados. Estudios realizados en el Reino Unido muestran que los patógenos más prevalentes son también el Streptococcus del grupo B y los bacilos gram negativos, así como el Streptococcus pneumoniae y la Listeria monocytogenes . Estos datos sugieren que tal vez sean ciertos factores (mas inherentes a los individuos afectados que a los agentes infecciosos en sí) los que determinan el nivel de las complicaciones inducidas, ya que no se ha demostrado aún, que la susceptibilidad de dichos gérmenes a los antibióticos varíe según su origen geográfico $(1,6)$.

Los factores de riesgo adicionales incluyen galactosemia (y/o otros errores innatos del metabolismo), hipoxia, acidosis fetal, y defecto en piel o mucosas como en el caso del mielomeningocele. Se presenta un mayor riesgo en recién nacidos pretérmino, partos tras una ruptura prematura de membranas con una evolución mayor a 18 horas, pacientes con antecedente de corioaminionitis o bacteremia, o maternas con edades inferiores a los 20 años principalmente hispanas o de raza negra. En la enfermedad de inicio temprano el período de incubación es menor a siete días y en la de inicio tardío, es de los siete días a tres meses de vida. En general se ha visto una recurrencia en un 1 a $3 \%$ de los neonatos después un tratamiento adecuado $(5,7)$. 


\section{Epidemiología}

La incidencia de meningitis bacteriana varía entre 0,1 a 0,4 por cada 1000 nacidos vivos. En los últimos años se ha observado una disminución de la mortalidad de un $29 \%$ a un $10 \%$, siendo la tasa de mortalidad actual de $12,4 \%$ en el Reino Unido y de 8,5\% en los Estados Unidos $(3,8)$.

\section{Descripción clínica}

Dada la inmadurez de los sistemas inmune y neurológico del recién nacido (que resultan ser aun más prominentes en los recién nacidos pretérmino), la clínica de esta condición por lo general no es lo suficientemente específica, como para permitir hacer un diagnóstico basados solamente en ella. De hecho, una de las recomendaciones mencionadas en la literatura es que cuando existen factores de riesgo o ante la más mínima sospecha de disfunción sistémica o neurológica, el diagnóstico se debe hacer muy temprano (9). Por ejemplo, en el caso clínico que al final se describe, los primeros signos clínicos fueron muy inespecíficos (dificultad leve en la succión, taquipnea y variabilidad en la frecuencia cardíaca) incluso antes de que se reportara fiebre, la cual nunca se presentó, o convulsiones que ocurrieron después de confirmado el diagnóstico a través de una punción lumbar. Esto contrasta claramente con la sintomatología observada en lactantes mayores o escolares, en quienes sí es más común que se reporte fiebre, cefalea, fotofobia, emesis, rigidez nucal, letargia, signos de Kerning y Brudzinski positivos, déficit neurológico focal o convulsiones $(10,11)$.

Las características propias de la presentación clínica también dependen de otros factores más específicos de cada paciente, tales como la edad gestacional, la edad postnatal, la presencia o no de problemas médicos y/o sistémicos concomitantes y la historia de tratamientos antibióticos recibidos previamente o durante el parto. Como ya se mencionó, los signos clásicos de la meningitis (en caso de presentarse), tienen una aparición tardía y por lo general son precursores de una mayor severidad del cuadro. La mortalidad también se ha asociado a valores bajos en la escala de coma de Glasgow: así, un puntaje igual o menor de seis implicará un riesgo nueve veces mayor que un puntaje igual o mayor de doce $(5,6)$.

La prevalencia de estos signos y/o síntomas ha sido evaluada en varios estudios clínicos. Así, la de hipoter- mia es del $62 \%$, la de letargia o irritabilidad el $52 \%$, la de anorexia o emesis el $48 \%$, la de distrés respiratorio el $41 \%$, la de abombamiento de fontanela el $28 \%$, la de convulsiones el $31 \%$ y la de rigidez de nuca en el $16 \%$ de los pacientes. Interesantemente, algunas de estas manifestaciones dependerán también de ciertas variables adicionales tales como el peso al nacer y/o la edad gestacional de los afectados. Por ejemplo, las convulsiones tienden a presentarse con mayor frecuencia en neonatos con un peso igual o mayor a $2500 \mathrm{~g}$ o con una edad gestacional mayor, lo cual podría deberse a una mayor madurez relativa en el sistema nervioso central de estos últimos en comparación con aquellos de mas bajo peso al nacer; mientras que los recién nacidos con peso $<1500$ g presentan una mayor frecuencia de hemorragias intracraneales y secuelas neurológicas severas, incluyendo un coeficiente intelectual residual menor. Por último, la ventriculitis se reporta hasta en un 40 a $90 \%$ de los pacientes cuyos estudios revelan la persistencia de bacterias en el LCR $(12,13)$.

\section{Secuelas y complicaciones}

Las secuelas severas a largo plazo varían entre un 12 a $29 \%$, con un compromiso leve de la función neurológica de $15 \%$ a $38 \%$, y la variación depende del estadio de la enfermedad e incluyen $(15,16)$ :

Fase inmediata ( $<3$ días):

- Convulsiones y/o status epiléptico

- Infartos y/o hemorragias cerebrales

- Aumento de la presión intracraneana (aunque la herniación es extremadamente rara dada la presencia de fontanelas abiertas).

- Síndrome de secreción inadecuada de la hormona antidiurética

Fase mediata (3-7 días):

- Colecciones subdurales y/o epidurales tales como el empiema y los higromas

Fase tardía (> 7 días)

- Síndromes convulsivos sintomáticos (relacionados con aéreas de gliosis o encefalomalacia).

- Déficits neurológicos inespecíficos tales como el retraso global en el desarrollo o la hidrocefalia; o específicos tales como los déficits motores tipo hemiparesia y/o quadriparesia. 
- Ventriculitis y/o cerebritis.

- Hipoacusia neurosensorial.

En general, las secuelas severas se presentan en un 9 a $15 \%$ de los sobrevivientes y las moderadas aunque significativas, en un $10 \%$. Aproximadamente $3,6 \%$ de los pacientes presentan hipoacusia neurosensorial, $2,7 \%$ hidrocefalia, y 5,4\% síndromes epilépticos sintomáticos comparado con $1,7 \%$ de la población no afectada.

La prevalencia de las secuelas severas depende también del tipo de microorganismo causante; así, en los cuadros producidos por bacilos gram negativos se pueden presentar hasta en un de $28 \%$ vs. $14,3 \%$, cuando el agente es el Streptococcus del grupo B; en los cuadros asociados a Listeria monocytogenes, este valor es del 7,7\%. En cuanto a los déficits cognitivos, existen estudios que sugieren un mayor compromiso cuando el cuadro es causado por Streptococcus del grupo B y microorganismos gram negativos $(17,18)$. Todos los pacientes que sobrevivan requieren de un completo tamizaje de las condiciones médicas tratables tales como la hidrocefalia o la hipoacusia, que de ser detectadas a tiempo mejoraran la calidad de vida. Finalmente, se ha observado que en los últimos diez años la mortalidad ha disminuido hasta en un 19\%, lo cual se ha relacionado con los tratamientos desarrollados y con la disminución de la prevalencia de los patógenos asociados a mayores complicaciones (18).

\section{Complicaciones}

Las complicaciones de meningitis bacteriana se relacionan con varios factores como edad y condiciones del hospedero, tiempo de evolución previo al diagnóstico y microorganismo causal, las más frecuentes son:

Aumento de presión intracraneana: con frecuencia se encuentra una presión intracraneana muy elevada que a menudo se manifiesta clínicamente como cefalea, vómito en proyectil, fontanela abombada y alteraciones del estado de conciencia. El papiledema es raro posiblemente debido a la corta duración del evento.

Síndrome de secreción inadecuada de hormona antidiurética (SIHAD): este síndrome descrito en todas las revisiones de la literatura, se asocia con retención hídrica y mayor riesgo de hipertensión endocraneana y convulsiones; se ha cuestionado últimamente, si se produce una "adecuada producción de hormona antidiurética" ante la presencia de hipovolemia no diagnosticada, que sólo con aporte hídrico apropiado no producirá los efectos deletéreos, posiblemente ante las pérdidas y pobre ingesta de líquidos, secundaria a la restricción. Este hecho es importante, ya que es necesario mantener la tensión arterial sistémica en niveles adecuados para prevenir la mala perfusión cerebral.

Hidrocefalia: fuera del periodo neonatal no es una complicación común de la meningitis. Si ocurre, casi siempre es comunicante y se produce como resultado de aracnoiditis adhesiva en las cisternas de la base del cerebro.

Efusiones subdurales: la alta frecuencia de efusiones subdurales y el hecho de que el líquido subdural se encuentra muy temprano en el curso de una meningitis bacteriana ha llevado a sugerir que la efusión es más efecto concomitante que una complicación de la inflamación meníngea. Aunque la efusión está presente en casi el $100 \%$ de los casos de meningitis bacteriana por H.influenzae tipo B y con menor frecuencia en meningitis por S.pneumoniae y N.meningitidis, es sintomática solo en $10 \%$ de los casos. Los síntomas más frecuentes, si los hay, son fiebre, letargia, aumento de perímetro cefálico, convulsiones y signos neurológicos focales.

Empiema subdural: da signos y síntomas similares a la efusión, pero usualmente son más severos. Para diferenciar estas dos entidades pueden ser útiles las punciones subdurales y estudio de neuroimágenes con medio de contraste yodado. El tratamiento de la efusión es conservador en la mayoría de casos. El empiema requiere tratamiento quirúrgico.

Absceso cerebral: es una complicación rara de meningitis por $H$. influenzae. Microorganismos poco usuales como Citrobacter diversus se asocian con absceso cerebral en $75 \%$ de los casos, especialmente en recién nacidos.

Ventriculitis: es una complicación rara pero muy grave de meningitis bacteriana, especialmente durante el periodo neonatal y está asociada a la alta mortalidad. Se presenta con mayor frecuencia en la meningitis producida por bacilos entéricos gram negativos. Los síntomas que se presentan son casi siempre debidos a la obstrucción del flujo del LCR, por los altos niveles de detritus y proteínas. Es difícil esterilizar el líquido y puede requerirse manejo quirúrgico.

Convulsiones: son relativamente comunes y se presentan en un 20-30\% de los pacientes durante el curso de 
la enfermedad. Desde el punto de vista fisiopatológico y de pronóstico es importante el tipo y momento de su presentación. Las convulsiones que ocurren tempranamente en el curso de la enfermedad, usualmente no están asociadas a secuelas, a diferencia de las que se presentan después del tercer día de iniciado el manejo, que tienen mayor posibilidad de estar asociadas con lesión parenquimatosa y con mayor número de secuelas.

Trastornos neurológicos focales: como hemiparesia, cuadriparesia, parálisis facial y alteraciones visuales pueden presentarse de manera temprana en el curso de la enfermedad, debidas a necrosis cortical, vasculitis o trombosis y correlacionarse con secuelas neurológicas posteriores. ${ }^{1}$

Hipoacusia: usualmente secundaria a inflamación del acueducto coclear y del nervio auditivo, puede llevar a sordera reversible o permanente en $5-30 \%$ de los pacientes.

Trombosis del seno longitudinal o cavernoso: es una complicación muy rara, asociada a altísima mortalidad. Se manifiesta con signos de edema cerebral severo y deterioro agudo del paciente

\section{Diagnóstico}

Los hallazgos clínicos más frecuentes no son específicos, hecho que confirma la dificultad de hacer un diagnóstico precoz de esta condición con base solamente en ellos. De hecho, la ausencia de signos neurológicos específicos durante la fase aguda del proceso infeccioso es uno de los factores que suele impactar el pronóstico, dado que a menos que la sospecha clínica sea alta, su aparición por lo general se asocia a un proceso más avanzado. Por lo general, los signos y/o síntomas iniciales más comunes son la disminución de la ingesta, succión pobre, letargia, irritabilidad, taquipnea o cianosis, bradicardia, hipotermia (o fiebre, la cual es menos común) o simplemente, un cambio en la actitud general del recién nacido; estos primeros hallazgos pueden ser tan sutiles, que por lo general son reportados mas por el personal de enfermería que por los médicos y/o especialistas en sí $(19,20)$.

Los demás signos y/o síntomas son los ya tradicionalmente asociados a esta condición, e incluyen: fiebre, irritabilidad, convulsiones y fontanela abombada, cuya frecuencia también suele depender de ciertas caracte- rísticas de los pacientes. Estos hallazgos se encuentran más frecuentes entre los recién nacidos con peso al nacer igual o mayor a $2500 \mathrm{~g}$, de otro lado hay otros inespecíficos como distensión abdominal, apnea o ictericia. Los cambios en el hemograma predominan entre los recien nacidos de menor peso. Una vez más, debe enfatizarse que la baja frecuencia de alteraciones neurológicas en los estadios tempranos de esta condición hace que el diagnóstico de la meningitis bacteriana sea mucho más difícil en los recién nacidos de bajo peso al nacer (20).

\section{Estudios paraclínicos}

El estudio del LCR es el "gold standard" para la confirmación de la meningitis bacteriana, motivo por el cual su obtención en forma adecuada debe ser una prioridad en tales casos. Su importancia se magnifica ante el hecho de que otros estudios bacteriológicos similares no alcanzan el mismo grado de especificidad/sensibilidad. Así por ejemplo, se ha reportado que sólo entre un $15 \%$ a $55 \%$ de los cultivos de sangre son positivos en estos pacientes y en un estudio realizado por la Academia Americana de Pediatría el porcentaje reportado fue $57 \%(21,22)$. Otro punto a tener en cuenta es la negativización que puede ocurrir en los cultivo a las pocas horas de la administración de antibiótico; de allí la polémica que se genera entre el beneficio de suministrar antibiótico empíricamente sin conocer el germen específico, después de haber realizado la toma de muestra de LCR $(23,24,25,26)$.

En cuanto a los criterios de los demás análisis disponibles en el LCR, el enfoque no es muy diferente al observado en pacientes de otras edades. Así, un recuento leucocitario en LCR mayor de 21 células por $\mathrm{mm} 3$ (predominancia de polimorfo-nucleares) implica una sensibilidad del $79 \%$ y una especificidad de un $81 \%$. Sin embargo, estas alteraciones clásicas pueden también estar ausentes en los estadios tempranos, de modo tal que si dicho recuento, o los estudios bioquímicos (nivel de glucosa y/o proteínas) son normales, debe entonces esperarse a la confirmación por cultivo del mismo, ya que la identificación del germen causal es un punto definitivo para el tratamiento éxitoso (Tabla 1).

Entre las diferentes ayudas para el diagnóstico y evaluación de la evolución del neonato y la meningitis bacteriana se pueden citar: 
TABLA 1. Rango de valores normales de estudio bioquímico de líquido cefalorraquídeo según Grupo de edad.

\begin{tabular}{lcccccc}
\hline \multicolumn{1}{c}{ Grupo de edad } & LEUC $(\mathbf{x ~ m l )}$ & CAN & $\begin{array}{c}\text { PMN } \\
\mathbf{( \% )}\end{array}$ & $\begin{array}{c}\text { Glucosa } \\
(\mathbf{m g ~ x ~ 1 0 0 m l )}\end{array}$ & $\begin{array}{c}\text { Glucosa } \\
\text { LCR/S* }\end{array}$ & $\begin{array}{c}\text { Proteinas } \\
(\mathbf{m g} \mathbf{~ 1 0 0 m l})\end{array}$ \\
\hline RN prematuro & $0-29$ & NI & $0-66$ & $24-63$ & 0,74 & $65-150$ \\
RN a término & $0-32$ & NI & $0-61$ & $34-119$ & 0,81 & $20-170$ \\
0-4 semanas & $0-50$ & $0-7,5$ & $0-15$ & $36-61$ & NI & $35-189$ \\
$>$ 4 semanas & $0-10$ & $<$ de1 & 0 & $45-65$ & $0,6-0,9$ & $14-45$ \\
\hline
\end{tabular}

Análisis citoquímico en LCR: la presencia de PMN en el LCR generalmente se considera anormal y usualmente es indicativa de infección bacteriana.

Tinción de gram: Es uno de los primeros y más importantes exámenes que debe hacerse en el LCR. La mayoría de casos de meningitis bacteriana tienen más de 105.000 unidades formadoras de colonias (UFC) por $\mathrm{ml}$. El $60 \%$ de las muestras tienen de 103.000 $105.000 \mathrm{UFC} / \mathrm{ml}$ y el $97 \%$ de las muestras que tienen más de 105.000 UFC muestran microorganismos gram positivo, siendo en su mayoría identificados como $\mathrm{H}$. influenzae.

Cultivos de LCR: siempre debe cultivarse el LCR en placas de agar sangre, de agar chocolate y en caldos de cultivo, dado que se han encontrado cultivos positivos de muestras de LCR tomadas en el curso inicial de la enfermedad, con un análisis citoquímico y tinción de gram no sugestivos de meningitis bacteriana. Se deben hacer cultivos especiales para micobacterias y hongos cuando la clínica y la epidemiología sugieran esta posibilidad.

Glucorraquia: es derivada del nivel de glicemia central con un desfase de 40-60 min ideal la toma de glucosa en sangre con este tiempo de anticipación, su valor normal es de $60-70 \%$ con un promedio de $66 \%$ del valor de la glicemia central. La presencia de hipoglucorraquia marcada ( $<$ de $20 \mathrm{mg} / \mathrm{dl}$ ) es altamente sugestiva de meningitis bacteriana.

Proteinorraquia: la concentración normal de proteínas en el LCR después del primer mes de edad es menor de $40 \mathrm{mg} / \mathrm{dl}$. En pacientes con meningitis bacteriana pueden encontrarse valores por encima de $100 \mathrm{mg} /$ dl. A pesar que en pacientes quienes han recibido manejo antibiótico antes de la punción lumbar (PL) puede haber algunas modificaciones, los hallazgos siguen siendo sugestivos de MB; las concentraciones de glucosa y proteínas permanecen alterados por varios días aún con manejo adecuado.

\section{Otros métodos diagnósticos en LCR}

- Ácido láctico: los niveles normales en el LCR son de $10-20 \mathrm{mg} / \mathrm{dl}$ y se alcanzan valores de $35-40 \mathrm{mg} /$ $\mathrm{dl}$ en infecciones del SNC de origen bacteriano.

- Proteina C-reactiva: sensibilidad de $80-100 \%$ y una especificidad de $86-96 \%$ para detectar meningitis bacteriana; sin embargo su utilidad es aun discutida.

- Aglutinación con partículas de Látex: detectan antígenos polisacáridos de H.influenzae tipo b, S.pneumoniae, N.meningitidis, E.coli K1, y Streptococcus grupo B. La prueba se puede realizar en $25-30$ min con sensibilidad de $95 \%$ y especificidad de $88-92 \%$.

- Inmunoelectroforesis por contracorriente: se hace este exámen para Streptococcus del grupo B, E. coli $\mathrm{K} 1, H$. influenzae tipo $\mathrm{b}, N$. meningitidis, $K$. pneumoniae, L. monocitógenes y S. tiphy . El procedimiento demora 30-45 min y su especificidad y sensibilidad promedio son de $90 \%$ sin embargo, parece ser menos efectiva que la aglutinación de partículas de látex.

Contraindicaciones para PL: las contraindicaciones que justifican aplazar o no practicar una punción lumbar ante sospecha de meningitis bacteriana e iniciar tratamiento son pocas, entre ellas están: compromiso cardiorrespiratorio importante, especialmente en neonatos, signos de hipertensión endocraneana, signos de focalización al exámen neurológico, infección cutánea en el área donde se practicará la PL, discracia sanguínea severa (hemofilia y trombocitopenia).

Indicaciones para repetir la PL: los casos en que se indica hacer una repetición de PL son: PL inicial dudosa, en el recién nacido: repetir a las 24-48 hrs y al 
finalizar el tratamiento, si no hay evidencia de buena respuesta clínica y en meningitis por neumococo a las $24-36$ horas $(3,6,30)$.

\section{Otros exámenes y procedimientos útiles en el diagnós- tico de meningitis bacteriana}

Cuadro hemático: en general se encuentra leucocitosis $>15000$ con neutrofilia y cayademia $>1500(3,6)$. Se ha considerado útil en el diagnóstico la relación de neutrófilos inmaduros/recuento total de neutrófilos. Valores > de 0,12 mostraron fuerte asociación con meningitis bacteriana $(3,36)$

Hemocultivos: existe un alto porcentaje de bacteremia en niños con meningitis bacteriana; se ha observado que el $80-90 \%$ de las bacteremias son por H.influenzae. Hay una correlación inversa entre la duración de la enfermedad antes del diagnóstico y la presencia de hemocultivos positivos. En relación a los hemocultivos en el recien nacido, se consideran la prueba de oro en el diagnóstico de sepsis y hace parte del estudio de meningitis en el neonato. Está indicado siempre tomarse al menos dos hemocultivos previo inicio o cambio de antibióticos, aunque tienen algunas limitantes por lo cual más que la decisión de inicio de antibióticos, es la herramienta ideal para dirigir la terapia antibiótica basados en los patrones de sensibilidad, y exige muestras de un volumen mínimo de $1 \mathrm{ml}$.

En sepsis temprana y tardía se deben tomar siempre dos hemocultivos de sitios periféricos diferentes incluyendo líneas arteriales (si estas llevan menos de ocho horas de insertadas) por la alta posibilidad de contaminación. La sensibilidad para identificación de bacteriemia en sepsis neonatal varía de un 50\%- $80 \%$. El mayor uso de antibióticos maternos ha contribuido a reducir la tasa de positividad de los cultivos en sepsis temprana.

Neuroimágenes (TAC y Resonancia magnética): aunque la tomografía axial computarizada (TAC) no se considera un exámen rutinario, debe hacerse en todo paciente, en quien se sospeche complicaciones (efusión subdural, dilatación ventricular, infarto cerebral, cerebritis, absceso etc.) durante el curso de una meningitis bacteriana. La toma de neuroimágenes se indica en los siguientes casos : convulsiones focales o generalizadas después del tercer día de tratamiento (tardías) o que sean recurrentes, signos de focalización en cualquier momento durante el curso de la enfermedad, depresión prolongada del estado de conciencia sin otros signos de hipertensión endocraneana, pacientes infectados por gérmenes no habituales como Acinetobacter y Staphylococcus aureus, Proteus sp, Salmonella y Citrobacter diversus e incremento rápido en el perímetro cefálico.

La práctica de neuroimágenes ha ayudado a entender la patogénesis de ciertas complicaciones de la meningitis bacteriana. Déficits neurológicos focales y convulsiones pueden producirse por varios mecanismos. El TAC ayuda a diferenciar etiología isquémica de aquella debida a infecciones localizadas como cerebritis, absceso y empiema y a aclarar causas de hipertensión endocraneana. Las neuroimágenes también son útiles para detectar fuentes contiguas potenciales de infección como sinusitis y mastoiditis.

Ecografía transfontanelar: útil en neonatos y lactantes menores para valorar complicaciones como hidrocefalia, higromas o efusiones subdurales.

Potenciales evocados auditivos de tallo cerebral: deben hacerse en todo paciente al terminar tratamiento de una meningitis bacteriana para detectar secuelas auditivas $(3,6,2)$.

Electroencefalograma: debe hacerse en todo paciente con convulsiones tempranas o tardías.

La obtención de un reporte preliminar a través de la coloración de gram tiene una baja sensibilidad y aun una menor especificidad; sin embargo, puede ser de importancia crítica en situaciones especiales. Por último, la técnica de detección de antígenos bacterianos a través de la Reacción en Cadena de Polimerasa (PCR) parece ser prometedora en neonatos, pero hasta ahora ha sido empleada solo en niños de mayores edades, y contra gérmenes específicos tales como la Neisseria meningitidis o el Streptococcus pneumoniae $(21,22)$.

Interesantemente, en un $2 \%$ de los casos, los microorganismos encontrados fueron discordantes entre las muestras de LCR y sangre, un hecho que claramente tendrá implicaciones a la hora de decidir el manejo antibiótico a largo plazo. Debe mencionarse que la meningitis bacteriana neonatal con frecuencia ocurre en ausencia de bacteremia, y aun en presencia de 
parámetros normales en el LCR. Se ha debatido a lo largo de los últimos años sobre si se debe o no realizar una punción lumbar en los neonatos en quienes se sospeche esta condición. Nuestra sugerencia es que a menos que haya una clara contraindicación en su toma (tales como diátesis hemorrágicas, dificultades técnicas específicas o estado general del paciente demasiado comprometido), y si hay un alto índice de sospecha clínica, la PL se debería indicar con el fin de mejorar el pronóstico $(10,11,27)$.

Punción lumbar: debe realizarse siempre en todo neonato con diagnóstico de sepsis tardía y bacteriemia documentada. En sepsis temprana se recomienda realizar la PL en todo neonato con signos clínicos de sepsis y/o meningitis. No es necesaria en caso de sospecha de sepsis neonatal temprana en un neonato asintomático. (Recomendación Grado B). Cerca del 28\% de los pacientes con meningitis tienen hemocultivos negativos.

\section{Tratamiento}

El eje principal del manejo es el de los antibióticos, el cual deberá complementar otras intervenciones de soporte regular, tales como la hidratación con líquidos endovenosos, control del disbalance hidroelectrolítico, nutrición, etc. De hecho, se ha demostrado que intervenciones tales como el ingreso temprano para monitoreo a la Unidad de Cuidado Intensivo Neonatal mejoran claramente la supervivencia y tienden a disminuir la severidad de las secuelas (28-30).

\section{Recomendaciones actuales para el tratamiento de la meningitis neonatal}

Primera línea antibiótica: ampicilina + aminoglucósido (gentamicina)

Indicaciones: sepsis temprana o sepsis de inicio tardío en neonato hospitalizado sin factores de riesgo para infección nosocomial y sin compromiso meníngeo, neonato con sospecha de infección temprana y en sepsis temprana con compromiso meníngeo sin microorganismo identificado en cultivos, se recomienda la asociación ampicilina + cefepima. Se debe tener presente que Listeria monocytogenes y Enterococcus sp son resistentes a las cefalosporinas de $3^{\circ}$ y $4^{\circ}$ generación, por lo cual se requiere manejo con ampicilina. El antibiótico de elección en Listeriosis es la ampicilina, y en sepsis por Streptococcus del grupo B es la penicilina $G$, en estos casos se recomienda continuar la gentamicina o aminoglucósido de elección durante siete días (sinergismo). Como política del comité de infecciones, se recomienda no utilizar como terapia empírica, cefalosporinas de tercera generación, aztreonam o quinolonas con el objetivo de disminuir la resistencia bacteriana, así como la emergencia de enterobacterias productoras de betalactamasas de espectro extendido (BLEEs).

\section{Segunda y tercera línea antibiótica}

Indicaciones: meningitis bacteriana tardía: vancomicina + cefepima. El uso limitado de vancomicina empírica previene la aparición tanto de Enterococcus como de S. epidermidis vancomicina resistentes. En relación a la duración del antibiótico se recomienda: en meningitis por microorganismo gram positivo: 14 días $y$ en meningitis por microorganismo gram negativo $y$ ventriculitis: 21 días

\section{Recomendaciones}

Dada a la frecuente ausencia de métodos microbiológicos que identifiquen a los microorganismos, el tratamiento antibacteriano deberá iniciarse de manera empírica en la gran mayoría de los casos. Se ha demostrado que terapia triple con una cefalosporina de cuarta generacion, penicilina y un aminoglucósido es muy eficaz. Esta combinación cubre los microorganismos más comunes; las cefalosporinas protegen contra la flora bacteriana del tracto genitourinario, la penicilina contra Streptococcus del Grupo B (S. agalactiae) y la Listeria monocytogenes, y el aminoglucósido contra aquellos gérmenes gram negativos que teóricamente no sean susceptibles a las cefalosporinas como la Klebsiella (22).

En aquellos pacientes en quienes se sospecha meningitis causada por organismos multirresistentes, casi siempre asociada a ciertos factores de riesgo epidemiológico específicos (como ocurre en el caso del Acinetobacter y la presencia de mielomeningocele), se indica el inicio empírico de meropenem (el cual reemplazaría a las cefalosporinas de tercera generación) hasta que el microrganismo sea completamente caracterizado (32-34).

La eliminación de los microorganismos del LCR depende de una adecuada antibioterapia, de su penetración al LCR, de la Concentración Inhibitoria Mínima (CIM) para cada germen, y de una dosificación 
segura y adecuada (35). En cuanto a las dificultades que tienen los aminoglucósidos en lograr una buena penetración en LCR, por fortuna, la inmadurez de la barrera hematoencefálica hace que esto no sea necesariamente un obstáculo insalvable en neonatos y se puede utilizar como terapia coadyudante. Sin embargo, la mayor dificultad terapéutica tiene que ver con que la dosis estándar requerida, que sea lo más cercano posible a la CIM de las bacterias a tratar, pues por lo general existe un margen muy pequeño entre las concentraciones terapéuticas y tóxicas, a diferencia de lo que ocurre con las cefalosporinas de tercera generación en las que la penetración en LCR es modesta, pero la dosis puede ser aumentada en forma segura, hasta llegar a ser mayor a la CIM $(2,36,37)$.

En cuanto a la terapia específica para cada microorganismo se recomienda: para el Streptococcus del grupo B se sugiere penicilina a altas dosis, tratamiento que debe ser endovenoso por lo menos durante dos semanas después de la negativización del cultivo de LCR -o hasta cuatros semanas si se desarrollan complicaciones tales como la ventriculitis $(2,37,38)$. Aunque esta bacteria es susceptible a penicilina, ampicilina y cefalosporinas de cuarta generación y usualmente resistente a los aminoglucósidos, no se ha reportado una diferencia comprobada entre el uso de penicilina o ampicilina. De todos modos, se sugiere inicialmente el uso de la primera para evitar el posterior desarrollo de resistencia bacteriana. El "Red Book" de la Academia Americana de Pediatría recomienda para los menores de siete días, dosis de penicilina $\mathrm{G}$ de 250.000 a $450.000 \mathrm{U} / \mathrm{kg} / \mathrm{día}$, administrada en tres fracciones y para los neonatos mayores de siete días, 450.000 a $500.000 \mathrm{U} / \mathrm{kg} /$ día divida en cuatro a seis fracciones. De usarse ampicilina, la dosis en menores de siete días es de 200 a $300 \mathrm{mg} / \mathrm{kg} /$ día divido en tres fracciones y para mayores de siete días es de $300 \mathrm{mg} / \mathrm{kg} /$ día dividida en cuatro a seis fracciones $(2,3,37)$.

Para las bacterias entéricas gram negativas, la combinación de ampicilina y aminoglucósidos ha sido utilizada por mucho tiempo; sin embargo, dichos agentes son resistentes a los aminoglucósido con frecuencia. Los cultivos de LCR suelen negativizarse en un tiempo mayor que en el caso de Streptococcus del grupo B y por lo tanto cuando se asocia la enfermedad a esta bacteria su morbimortalidad es mayor $(2,39)$. El aminoglucósido intraventricular no se usa de rutina; sin embargo, puede ser considerado en caso de ventriculitis obstructiva complicada, aunque su aprobación está en discusión. Cefotaxime es también el agente de elección para Pseudomona aeuriginosa, en cuyo caso debera ser suministrado junto a un aminoglucósido.

El tratamiento para la Listeria monocytogenes debe iniciarse con ampicilina y un aminoglicósido endovenoso tipo gentamicina y si hay una respuesta clínica favorable, se continúa solo con la ampicilina. La terapia para el Streptococcus pneumoniae se basa en el uso de penicilina (250.000 a $450.000 \mathrm{UI} / \mathrm{kg} /$ día divida en cuatro a seis fracciones) o ampicilina y cefotaxime (225-300 mg/kg/día en tres fracciones) o ceftriaxona $(100 \mathrm{mg} / \mathrm{kg} /$ día en una a dos tomas); si en el antibiograma no hay susceptibilidad a estos antimicrobianos se deben hacer las pruebas para valorar la sensibilidad a vancomicina (60 mg/ kg/día en cuatro fracciones), rifampicina ( $20 \mathrm{mg} / \mathrm{kg} /$ día en dos tomas), meropenem (120 mg/kg/día en tres tomas) y cloranfenicol (75$100 \mathrm{mg} / \mathrm{kg} /$ día en cuatro fracciones) $(2,37,39,40)$.

En neonatos, no se encontraron reportes de estudios relacionados con el uso de terapia adyuvante con corticoesteroides como mecanismo que ayude a disminuir los procesos inflamatorios y el edema cerebral (41-43). La dosis de cada medicamento antibiótico depende del peso del neonato y la edad gestacional corregida; se debe tener en cuenta que en pacientes con falla renal se debe ajustar la dosis según su función renal. (Tabla 2) (37).

En todos los casos y de ser posible, se sugiere realizar una punción lumbar entre el primer y tercer día del inicio de antibioticoterapia dependiendo de la clínica del paciente, ya que cuando el cultivo es persistentemente positivo hay un alto riesgo de complicaciones y el pronóstico es más pobre. En este caso se deberá reevaular el antibiótico escogido, su dosis y forma de administración (o estudios farmacoquinéticos si es posible). En estos casos, también se sugiere la toma de neuroimágenes para descartar la presencia de colecciones u otras complicaciones que indiquen una prolongación del tratamiento tales como el empiema subdural, absceso cerebral o ventriculitis $(44,45)$. Si se observa una clara respuesta clínica favorable al finalizar el tratamiento no es necesario realizar PL; un estudio realizado en Inglaterra sugiere que se requiere solo en aproximadamente un $18 \%$ de los casos $(4,5,19,37)$.

\section{Prevención}

La prevención se basa en la detección y tratamiento precoz de la colonización en gestantes y en la realiza- 
TABLA 2. Dosis de antibiótico para meningitis neonatal bacteriana según el peso y edad gestacional corregida $(\mathrm{mg} / \mathrm{kg} / \mathrm{dosis}$ o U/ $\mathrm{kg} / \mathrm{dosis}$ en el rango de dosis mínima) e intervalos de administración.

\begin{tabular}{|c|c|c|c|c|}
\hline ANTIBIÓTICO & 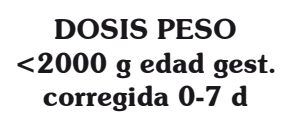 & $\begin{array}{l}\text { DOSIS PESO } \\
>\mathbf{2 0 0 0} \text { g edad gest. } \\
\text { corregida } 0-7 \mathrm{~d}\end{array}$ & $\begin{array}{l}\text { DOSIS EN PESO } \\
<2000 \mathrm{~g} \text { edad gest. } \\
\text { corregida }>\mathbf{~ d}\end{array}$ & $\begin{array}{l}\text { DOSIS EN PESO } \\
<2000 \mathrm{~g} \text { edad gest } \\
\text { corregida }>7 \mathrm{~d}\end{array}$ \\
\hline \multicolumn{5}{|c|}{ Penicilinas } \\
\hline Ampicilina & $50 \mathrm{mg} / 12 \mathrm{~h}$ & $50 \mathrm{mg} / 8 \mathrm{~h}$ & $50 \mathrm{mg} / 8 \mathrm{~h}$ & $50 \mathrm{mg} / 6 \mathrm{~h}$ \\
\hline Penicilina-G & $50,000 \mathrm{U} / 12 \mathrm{~h}$ & $50,000 \mathrm{U} / 8 \mathrm{~h}$ & $50,000 \mathrm{U} / 8 \mathrm{~h}$ & $50,000 \mathrm{U} / 6 \mathrm{~h}$ \\
\hline Oxacilina & $50 \mathrm{mg} / 12 \mathrm{~h}$ & $50 \mathrm{mg} / 8 \mathrm{~h}$ & $50 \mathrm{mg} / 8 \mathrm{~h}$ & $50 \mathrm{mg} / 6 \mathrm{~h}$ \\
\hline \multicolumn{5}{|c|}{ Cefalosporinas } \\
\hline Cefotaxime & $50 \mathrm{mg} / 12 \mathrm{~h}$ & $50 \mathrm{mg} / 8 \mathrm{~h}$ & $50 \mathrm{mg} / 8 \mathrm{~h}$ & $50 \mathrm{mg} / 6 \mathrm{~h}$ \\
\hline Ceftriaxona & 50 mg / día & $50 \mathrm{mg} /$ día & 50 mg / día & 75 mg /día \\
\hline
\end{tabular}

ción de la PL oportuna, ante síntomas en el neonato con clínica de infección en las primeras 72 horas o en todos los recién nacidos con sospecha de infección tardía. Los métodos utilizados para la prevención son: la antibióticoterapia profiláctica temprana al momento del nacimiento, la vacunación (Streptococcus del grupo b, Escherichia coli) y finalmente medidas de higiene que prevengan la diseminación de la enfermedad producida por microorganismos tales como el Staphylococcus epidermidis $(4,46)$.

En Estados Unidos se ha disminuido la incidencia de la enfermedad de inicio temprano de 1 a 0,5 casos por cada 1.000 nacidos vivos, especialmente los relacionados con el Streptococcus del grupo B, con la profilaxis a las madres durante el parto (46-48). El Centro de Control de Enfermedades y Prevención sugiere que la quimioprofilaxis respecto al Streptococcus del grupo $\mathrm{B}$ debe ser suministrada a: gestantes entre 35 a 37 semanas con colonización vaginal y rectal, gestantes que han presentado bacteruria o cultivo positivo para Streptococcus del grupo B durante la gestación, o que han tenido antecedentes de un recién nacido afectado por esta enfermedad misma bacteria y gestantes en las que no se ha realizado tamizaje y/o que presenten factores de riesgo tales como una gestación menor de 37 semanas, ruptura prematura de membranas mayor a 18 horas o una temperatura mayor de $38^{\circ} \mathrm{C}$ al momento del parto (49).

La quimioprofilaxis durante el parto se realiza con penicilina G intravenosa 5`000.000 UI dosis de carga y se continua $2^{\prime} 500.000$ UI cada cuatro horas hasta el nacimiento. En pacientes alérgicas a la penicilina se recomiendan $2 \mathrm{~g}$ IV de cefazolina seguidos de $1 \mathrm{~g}$ cada ocho horas. Si el riesgo de infección es elevado se prefiere vancomicina $1 \mathrm{~g}$ IV cada doce horas hasta el nacimiento. En mujeres con alto riesgo a anafilaxia con penicilina se sugiere clindamicina $900 \mathrm{mg}$ cada ocho horas. A los recién nacidos de madres a las que se les realizó profilaxis, que presenten signos de sepsis, se les debe realizar valoración diagnóstica e iniciar terapia empírica; si la edad gestacional es menor a 35 semanas o la profilaxis materna durante el parto fue inferior a cuatro horas, se debe observar estrictamente mínimo por 4 horas, vigilando si aparecen signos de sepsis $(50,51)$. La prevención de infecciones por Listeria monocytogenes se realiza con la cocción adecuada de la carne, lavar verduras crudas, separar las carnes crudas de las verduras, no consumir productos lácteos no pasteurizados y lavar manos, cuchillos y tablas para picar después de exposición a alimentos crudos. No se realiza profilaxis si se realiza cesarea y aún no ha roto membranas (52).

\section{Discusión}

Pese a los grandes esfuerzos y avances en la terapéutica para el tratamiento de la meningitis bacteriana neonatal, la tasa de morbimortalidad no se ha reducido a niveles satisfactorios. Se ha observado que por la clínica errática de la meningitis neonatal bacteriana y que por el diagnóstico que se fundamenta en el cultivo de LCR, es importante que el tratamiento se base en 
los resultados del antibiograma. Sin embargo, una vez tomada la muestra el tratamiento empírico con penicilina o ampicilina más una cefalosporina de tercera generación y un aminoglucósido tipo gentamicina, ha mostrado una adecuada respuesta clínica. Las secuelas severas a largo plazo se presentan en un 12 a $29 \%$ y se han asociado en su mayoría a bacilos gram negativos. La prevención se hace vacunando a los gestantes con alto riesgo de infección con Streptococcus del grupo $\mathrm{B}$ y E. coli y tomando medidas de higiene adecuadas para evitar la infección nosocomial.

Se requieren de estudios analíticos controlados que generen opciones con validéz científica para el manejo de esta patología. Ha sido difícil realizar estudios que ayuden a determinar cual es el pronóstico de la enfermedad debido a la limitación en el seguimiento de los casos que ayuden a determinar las secuelas; se deben definir las variables que midan el grado de afectación durante la enfermedad y posterior a ella y la mortalidad si se presenta. Es importante crear una red nacional para poder recolectar toda la información del país, la que ayudaría a determinar cual es el impacto epidemiológico de la enfermedad, cuales son los factores de riesgo, como detectar los casos más rápido, que bacterias están ocasionando la infección y si hay meningitis de origen no bacteriano y finalmente a evaluar la respuesta a la terapéutica en nuestro medio.

\section{Caso clínico}

A continuación presentamos un caso clínico reciente de los archivos médicos del Jackson Memorial Hospital de Miami, que ilustra la típica evolución clínica de esta enfermedad. Ello incluye un énfasis en lo inespecífico de sus hallazgos semiológicos al momento de su aparición, lo tórpido y complejo de su evolución, así como la eventual severidad de su compromiso clínico y sus posibles secuelas. También se puede asociar la infección con una falta de cuidado prenatal adecuado por el no conocimiento del mismo, posiblemente debido al nivel socioeconómico de la madre.

La madre del neonato tuvo un embarazo no deseado, sin complicaciones médicas específicas excepto por un episodio de dolor abdominal, que fue atribuido a una amenaza de parto prematuro en la semana 23 de gestación. La madre es afroamericana, de 16 años de edad, primigrávida, y quien no recordaba la fecha de su último período menstrual, con antecedente de asma controlada sin necesidad de medicamentos y vaginosis bacteriana tratada meses previos. En las primeras semanas de gestación refiere un accidente automovilístico. El primer contacto documentado con los servicios de salud ocurre la semana 23 de gestación y los estudios paraclínicos en esa visita fueron normales. No aparecen más datos en su historia clínica, lo cual es altamente sugestivo de una ausencia de cuidado prenatal adecuado. El parto es atendido en un hospital, en la semana 35 de gestación, el peso del neonato fue de 3,220 g y todos los demás valores antropométricos estuvieron acordes con esta variable (CC: 30,5 cm). Los valores de la escala Apgar fueron 9 y 9 , y al momento del nacimiento no se reportaron dificultades específicas, describiéndosele como neonato sano, alerta, activo, con buen llanto y un buen tono muscular. Los signos vitales también fueron normales.

A las diecisiete horas de vida, el servicio de enfermería reporta que el recién nacido presenta episodios intermitentes de taquipnea y taquicardia. Los signos vitales reportados en ese momento fueron: FR entre 70 a 112 (siendo previamente de 56), pulso de 160 a 180 (previa de 164) y una temperatura $36,3 \mathrm{C}^{\circ}$ y se evidencia alteración en la succión. El recién nacido se traslada a cuidado intensivo y se le ordena placa de tórax que es reportada como normal, se repite a las seis horas evidenciando edema pulmonar e infiltrados bilaterales para hiliares y de lóbulos inferiores, compatibles con neumonía. Se inicia manejo médico con soporte ventilatorio e intubación y se considera proceso séptico. Pocas horas después presenta deterioro en su estado general y episodios convulsivos, los cuales se asociaban a cianosis, movimientos estereotipados de las extremidades inferiores tipo pedaleo y desviación de la mirada. Se decide manejo con fenobarbital, el cual en algunas ocasiones requirió ser suplementado con fosfenitoína $y$ benzodiazepinas. El electroencefalograma (EEG) en ese momento mostró enlentecimiento de los ritmos de fondo, así como una marcada actividad epiléptica unilateral, incluyendo la existencia de PLED's (periodic lateralizing epileptiform discharges) (Figura 1A y B).

Los resultados de los estudios de laboratorio fueron: la tinción de gram del hemocultivo fue positiva para bacterias gram positivas tipo cocos en cadenas, y el análisis de LCR reportó 370 leucocitos por mm3 (sin eritrocitos) con un diferencial de $10 \%$ de neutrófilos, $10 \%$ de linfocitos, $40 \%$ de eosinófilos y $40 \%$ de monocitos; los valores de glucosa fueron menores de $20 \mathrm{mg} / \mathrm{dl}$ y los de proteína de $300 \mathrm{mg} / \mathrm{dl}$. Los cultivos de sangre y LCR fueron positivo para Streptococcus agalactiae. A 


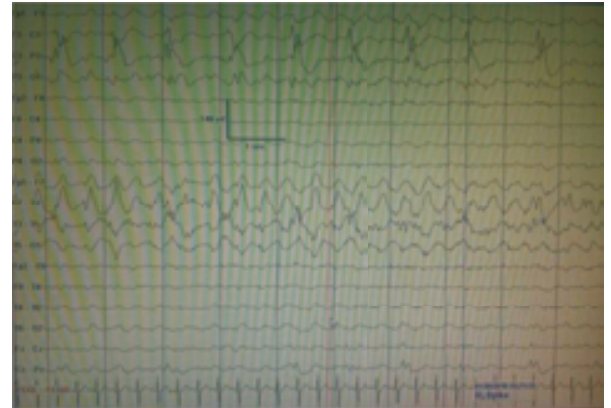

A

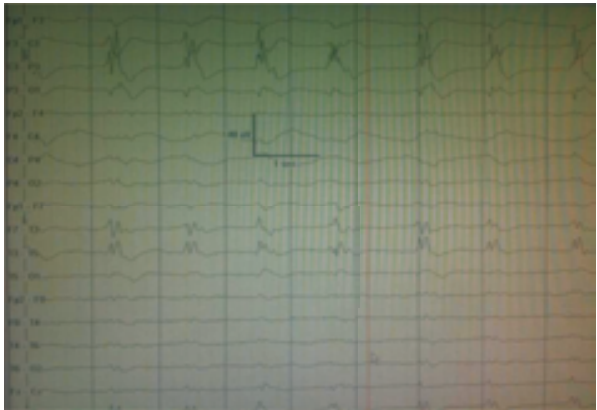

B

FIGURA 1. Electroencefalograma. a) Actividad epiléptica unilateral con PLED's (periodic lateralizing epileptiform discharges) y b) Enlentecimiento de los ritmos de fondo.

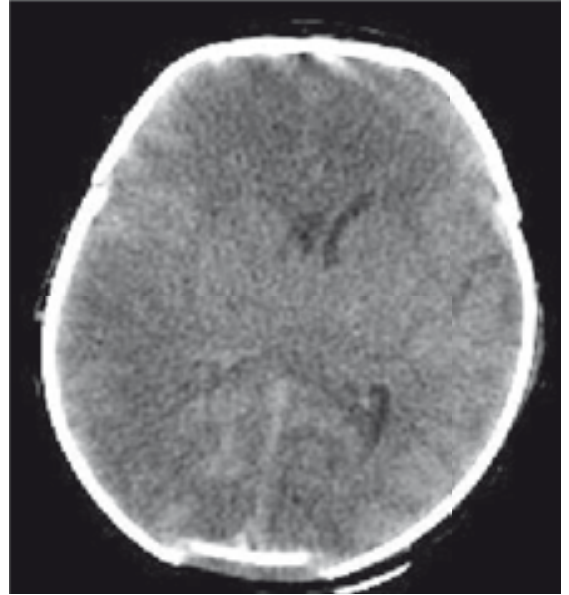

A

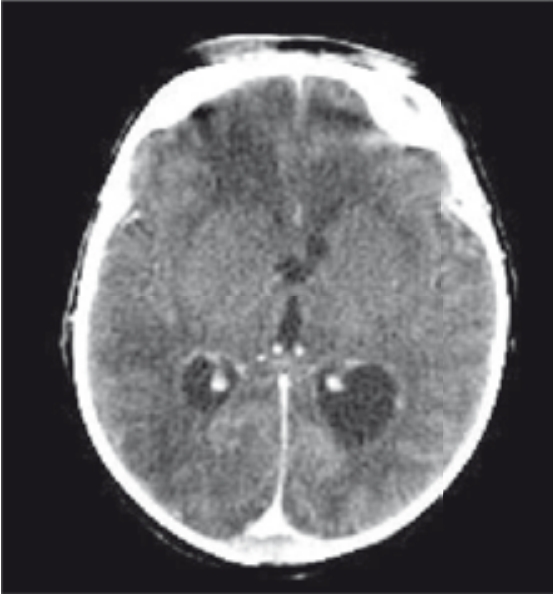

B

FIGURA 2. Tomografia Axial Computarizada cerebral simple. a) Se evidencia edema difuso cerebral marcado y b) Áreas de isquemia severa.

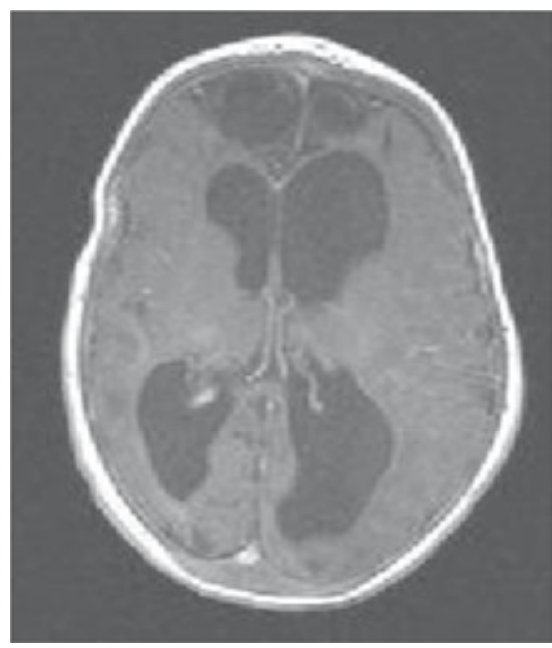

A

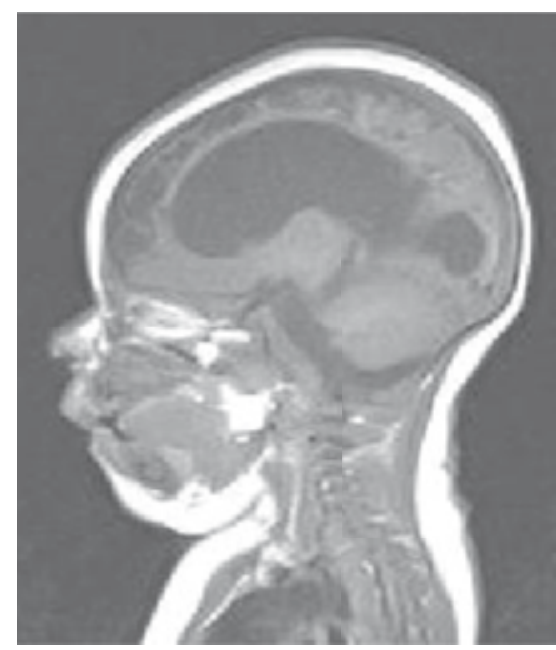

B

FIGURA 3. Resonancia Magnética Nuclear cerebral. a) Se evidencia atrofia difusa y b) Múltiples áreas de encefalomalacia quística. 
las 72 horas el LCR se examinó de nuevo y el cultivo ya se había negativizado, pero los leucocitos seguían estando elevados (850 x mm3) con un diferencial de $88 \%$ de neutrófilos y un $12 \%$ de linfocitos y el valor de la glucosa seguía bajo $(25 \mathrm{mg} / \mathrm{dl})$.

El paciente presentó una evolución clínica muy tórpida, caracterizada por episodios convulsivos recurrentes y prolongados, los cuales en cierto momento necesitaron de una combinación de tres agentes antiepilépticos. El EEG en algunos momentos mostró menos actividad, y en otros recurrencia de los episodios convulsivos. Los estudios de imagenología mostraron un edema difuso cerebral muy marcado en los estadios iniciales con evidencia de isquemia severa (Figuras $2 \mathrm{~A}$ y B). La resonancia magnética cerebral de control realizada a los 45 días de vida mostró severos cambios residuales tipo atrofia difusa y múltiples áreas de encefalomalacia quística (Figura 3A y B). Su evolución clínica fue muy tórpida, con retardo en el neurodesarrollo psicomotor, aparición progresiva y persistencia de severa espasticidad con hiperreflexia, irritabilidad y caída en los percentiles del crecimiento cefálico. Los estudios de seguimiento a nivel visual y auditivo también fueron anormales, observándose secuelas severas en estas áreas. Por todos hallazgos se piensa en un pronóstico general reservado.

\section{Referencias}

1. Heath P T, Nik N K, Yusoff, Baker C J. Neonatal Meningitis. Archives of Disease in Childhood. Fetal Neonatal. 2003;88:173-178

2. Klein J O. Bacterial Sepsis and Meningitis. In: Remington J S, Klein J O, eds. Infectious Diseases of the Fetus and Newborn Infant. 5th ed. Philadelphia, P A: W B Saunders. 2001:943998.

3. Instituto Nacional de Salud, Ministerio de la Protección Social. República de Colombia. Protocolo de Vigilancia de $\mathrm{Me}$ ningitis Bacteriana. 2002:1-16.

4. American Academy of Pediatrics. Report of the Committee on Infectious Diseases Red Book. 2006. 27th edition.

5. Stevens J P, Eames M, Kent A, Halket S, Holt D, Harvey D. Long Term Outcome of Neonatal Meningitis. Archives Disease in Childhood. 2003;88:179-184.

6. Scarborough M, Thwaites G E. The Diagnosis and Management of Acute Bacterial Meningitis in Resource-Poor Settings. Lancet Neurology. 2008;7:637-648.

7. Eva P, Galiza P T. Heath. Improving the Outcome of Neonatal Meningitis. Current Opinion in Infectious Diseases. 2009;22:229-234.

8. Andersen J, Christensen R, Hertel J. Clinical Features and Epidemiology of Septicaemia and Meningitis in Neonates Due to Streptococcus agalactiae in Copenhagen Country. Denmark: a 10 year survey from 1992 to 2001. Acta Paediatrica. 2004;93:1334-1339
9. Delgado Noguera, Mario F. Percepciones de Signos de Alarma en Enfermedad Neonatal de los Cuidadores y Trabajadores de la Salud en Guapi, Colombia. Revista de Salud pública. 2007;9:39-52

10. Iordan F A, Cant A J. When to do a Lumbar Puncture. Archives Disease in Childhood. 2002;87:235-237.

11. Visser V E, Hart R T. Lumbar Puncture in the Evaluation of Suspected Neonatal Sepsis. Journal of Pediatrics. 1980;96:1063-106

12. Branco R G, Amoretti C F, Tasker R C. Meningococcal Disease and Meningitis. Journal of Pediatrics. 2007;83:46-53.

13. Jornada V L, Moraes G A. Clinical Outcome of Neonatal Bacterial Meningitis according to Birth Weight. Archives of Neuropsiquiatry. 2007;65:1149-1153.

14. Amer A L. Neonatal Group A Streptococcal Meningitis: A Case Report and Review of the Literature. Cases Journal. 2008;1:108.

15. Oostenbrink R, Moons K G, Derksen-Lubsen G, Grobbee D E, Moll H A. Early Prediction of Neurological Sequelae or Death after Bacterial Meningitis. Acta Pediatrica. 2002;91:391-8.

16. Fitzhardinge P M, Kazemi M, Ramsay M, Stern L. Long-term Sequelae of Neonatal Meningitis. Developmental Medicine and Child Neurology. 2008;16:3-10.

17. Benjamin D K, DeLong E, Cotten C M, Garges H P, Steinbach W J, Clark R H. Mortality Following Blood Culture in Premature Infants: Increased with Gram-negative Bacteremia and Candidemia, but not Gram-positive Bacteremia. Journal of Perinatology. 2004;24:175-180.

18. Benjamin D K Jr, DeLong E R, Cotten C M, Garges H P, Clark R H. Postconception Age and Other Risk Factors Associated with Mortality Following Gram-negative Rod Bacteremia. Journal of Perinatology. 2004;24:169-174.

19. Kumar S. Missed and Delayed Diagnosis of Neonatal Meningitis. Indian Pediatrics. 2004;41:959-960.

20. Stoll B J, Hansen N I, Adams-Chapman I. Neurodevelopmental and Growth Impairment Among Extremely Low-birthweight Infants with Neonatal Infection. Journal of American Medical Association. 2004;292:2357-2365.

21. Benjamin F Jr. Lenfestey R. Cultures, Blood Cultures, and Cerebrospinal Fluid Parameters? Pediatrics. 2006;117;10941100.

22. Morven S E, Nizet V, Carol J B. Infectious Diseases of the Fetus and Newborn Infant. 2006;6:403-464.

23. Strang J R, Pugh E J. Meningococcal Infections: Reducing the Case Fatality Rate by Giving Penicillin before Admission to Hospital. British Medical Journal. 1992;305:141-143.

24. Hahne S J, Charlett A, Purcell B. Effectiveness of Antibiotics Given before Admission in Reducing Mortality from Meningococcal Disease: Systematic Review. British Medical Journal. 2006;332:1299-1301.

25. Sorensen H T, Nielsen G L, Schonheyder H C. Outcome of Prehospital Antibiotic Treatment of Meningococcal Disease. Journal of Clinical Epidemiology. 1998;51:717-721.

26. Sudarsanam T D, Rupali P, Tharyan P. Preadmission Antibiotics for Suspected Cases of Meningococcal Disease. Cochrane Database Systematic Reviews. 2008(1).

27. Agarwal R, Emmerson A J. Should Repeat Lumbar Punctures be Routinely Done in Neonates with Bacterial Meningitis? Results of a Survey into Clinical Practice. Archives Disease in Childhood. 2001;84:451-452.

28. Centers for Disease Control and Prevention. Prevention of Perinatal Group B Streptococcal Disease. Revised Guidelines from CDC. MMWR Recommendations and Reports. 2002;51:1. 
29. Annette K, Ansong P, Smith B Daniel K. Benjamin C, Reese H, Clark D, Jennifer S, Li C. Michael C A, Mangum B, Harmony P, Garges A, Daniel K. Benjamin Jr. Group B Streptococcal Meningitis: Cerebrospinal Fluid Parameters in the Era of Intrapartum Antibiotic Prophylaxis. Early Human Development. 2009;85:5-7.

30. Echandia C A, Ruiz, J G. Apgar Bajo al Nacer y Convulsiones Neonatales: Desarrollo Motor Grueso en el Primer Año de Vida. Colombia Medica. 2006;37:21-30.

31. Prasad K, Kumar A, Singhal T, Gupta P K. Third Generation Cephalosporins Versus Conventional Antibiotics for Treating Acute Bacterial Meningitis. Cochrane Database Systematic Reviews. 2007:4.

32. Evangelia L, Heracles D D, Antonaki G, Foustoukou M, and Lacovidou N. Case Report Bacillus Cereus Meningitis in a Term Neonate. The Journal of Maternal-Fetal and Neonatal Medicine. 2009;22: 458-461.

33. Gavin P J, Thomson R B Jr, Horng S J, Yogev R. Neonatal Sepsis Caused by Streptococcus Bovis Variant (biotype II/2): Report of a Case and Review. Journal of Clinical Microbiology. 2003;41:3433-5.

34. Boyer-Mariotte S, Duboc P, Bonacorsi S, Lemeland J F, Bingen E, Pinquier D. CTX-M-15-Producing Escherichia coli in Fatal Neonatal Meningitis: Failure of Empirical Chemotherapy. Journal of Antimicrobial Chemotherapy. 2008;62:1472-1474.

35. Malik G K, Yadav A, Trivedi R, Srivastava A, Prasad K N, Gupta R K. Temporal Alterations in Brain Water Diffusivity in Neonatal Meningitis. Acta Pædiatrica. 2009;98:1426-1432.

36. .Stoll B J, Hansen N, Fanaroff A A. Changes in Pathogens Causing Early-onset Sepsis in Very-low-birth-weight Infants. New England Journal of Medicine. 2002;347:240-7.

37. Muller M. Meningitis, Bacterial: Treatment and Medication. E-medicine 2009, Oct 5. Available from: http://emedicine. medscape.com/article/961497-treatment.

38. Onoyama S, Ogata R, Wada A, Saito M, Okada K, Harada T. Neonatal Bacterial Meningitis caused by Streptococcus gallolyticus subsp. pasteurianus. Journal of Medical Microbiology. 2009;58:1252-4.

39. Araujo O R. Cefepime Restriction Improves gram-negative Overall Resistance Patterns in Neonatal Intensive Care Unit. Brazilian Journal of Infectious Disease. 2007;11:277-280.

40. Y Haimi-Cohen, Amir J. The Use of Imipenem-cilastatin in Neonatal Meningitis caused by Citrobacter diversus. Acta Pediatrica. 2008;82:530-532.

41. Daoud A S, Batieha A, Al-Sheyyab M. Lack of Effectiveness of Dexamethasone in Neonatal Bacterial Meningitis. European Journal of Pediatrics. 1999;158:230-3.

42. Schaad U B, Lips U, Gnehm H E. Dexamethasone Therapy for Bacterial Meningitis in Children. Lancet. 1993;342:457461.

43. Van de Beek D, de Gans J, McIntyre P, Prasad K. Corticosteroids for acute bacterial meningitis. Cochrane Database Syst Rev 2007. 1
44. Yikilmak A, Taylor G A. Sonographic findings in Bacterial Meningitis in Neonates and Young Infants. Pediatric Radiology. 2008;38:129-137.

45. Daneman A, Epelman M, Blaser S. Imaging of the Brain in Full-term Neonates: Does Sonography Still Play a Role? Pediatric Radiology 2006;36:636-646.

46. Bizzarro M J, Dembry L M, Baltimore R S. Changing Patterns in Neonatal Escherichia coli Sepsis and Ampicillin Resistance in the Era of Intrapartum Antibiotic Prophylaxis. Pediatrics. 2008;121:689-96.

47. Silva B V. Neonatal Meningitis Caused by Atypical Streptococcus pneumoniae: Case Report and Review. Revista Chilena de Infectologia. 2006;23:346-350

48. Cortes H. Prevención de la Infección Neonatal por Estreptococo del Grupo B: ¿Es Necesaria en Nuestro Medio? Revista Colombiana de Obstetricia y Ginecología. 2005;56:231-238.

49. Campodonico O L, Doren V A, Cruz O M, Abarzua C F. Profilaxis de Sepsis Neonatal Precoz por Streptococcus agalactiae (grupo b) Basada en Vacunas: Revisión de la Literatura. Revista Chilena de Obstetricia y Ginecología. 2008;73:411-418.

50. Bassler, Dirk, Stoll, Barbara J, Schmidt, Barbara, Asztalos, Elizabeth V, Roberts, Robin S, Robertson, Charlene M T, Sauve, Reg S, for the Trial of Indomethacin Prophylaxis in Preterms Investigators, Using a Count of Neonatal Morbidities to Predict Poor Outcome in Extremely Low Birth Weight Infants: Added Role of Neonatal Infection Pediatrics. 2009;123:313318.

51. Ungerer R L, Lincetto O,McGuire W, Saloojee H, Gulmezoglu A M. Prophylactic Versus Selective Antibiotics for Term Newborn Infants of Mothers with Risk Factors for Neonatal Infection. Cochrane Database of Systematic Reviews. 2004;4.

52. Annette K, Ansong P, Smith B. Group B streptococcal Meningitis: Cerebrospinal Fluid Parameters in the Era of Intrapartum Antibiotic Prophylaxis. Early Human Development. 2007;85:5-7.

53. Powell K S, Eskenazi A E. Normalization of Plasma Arginine Vasopressin Concentrations when Children with Meningitis are Given Maintenance Plus Replacement Fluid Therapy. Journal of Pediatrics. 1990;117:515-22.

54. Singhi S C, Srinivas B. Fluid Restriction does not improve the Outcome of Acute Meningitis. The Pediatric Infectious Disease Journal. 1995;14:495-503.

55. Kaplan S 1. Clinical Manifestations, Diagnosis and Prognostic Factors of Bacterial Meningitis. Infectious Diseases Clinics of North America. 1999;13:579-90.

56. Rodriguez A F, Kaplan S L. Cerebrospinal Fluid Values in the Very Low Birth Weight Infants. Journal of Pediatrics. 1990;116:971-74.

57. Palau J M. Meningitis Bacteriana: Bases Racionales del Tratamiento. Acta Pediatrica. 1992;(1):56-58. 